Effect of $\mathrm{V}$ and $\mathrm{N}$ on the microstructure evolution during continuous casting of steel

This article has been downloaded from IOPscience. Please scroll down to see the full text article.

2012 IOP Conf. Ser.: Mater. Sci. Eng. 27012059

(http://iopscience.iop.org/1757-899X/27/1/012059)

View the table of contents for this issue, or go to the journal homepage for more

Download details:

IP Address: 134.83.1.241

The article was downloaded on 16/01/2012 at 10:42

Please note that terms and conditions apply. 


\title{
Effect of $\mathbf{V}$ and $\mathbf{N}$ on the microstructure evolution during continuous casting of steel
}

\author{
B Santillana ${ }^{1,2,3}$, D G Eskin ${ }^{4}$, R Boom ${ }^{1,2,3}$ and L Katgerman ${ }^{2}$ \\ ${ }^{1}$ Casting Metallurgy Flat products group, Steelmaking and Continuous Casting \\ department, Tata Steel RD\&T, POBox 10000, 1970CA, IJmuiden, The Netherlands \\ ${ }^{2}$ Department of Materials Science and Engineering, Delft University of Technology; \\ Delft, The Netherlands \\ ${ }^{3}$ Materials innovation institute M2i, Mekelweg 2, 2628CD, Delft, The Netherlands \\ ${ }^{4}$ BCAST, Brunel University, Uxbridge UB8 3PH, U.K.
}

E-mail: begona.santillana@tatasteel.com

\begin{abstract}
Low Carbon (LC) steel is not expected to be sensitive to hot tearing and/or cracking while microalloyed steels are known for their high cracking sensitivity during continuous casting. Experience of the Direct Sheet Plant caster at Tata Steel in Ijmuiden (the Netherlands), seems to contradict this statement. It is observed that a LC steel grade has a high risk of cracking alias hot tearing, while a High Strength Low Alloyed (HSLA) steel has a very low cracking occurrence. Another HSLA steel grade, with a similar composition but less $\mathrm{N}$ and V is however very sensitive to hot tearing. An extreme crack results in a breakout. A previous statistical analysis of the breakout occurrence reveals a one and a half times higher possibility of a breakout for the HSLA grade compared to the LC grade. HSLA with extra N, V shows a four times smaller possibility of breakout than LC. This study assigns the unexpected effect of the chemical composition on the hot tearing sensitivity to the role of some alloying elements such as $\mathrm{V}$ and $\mathrm{N}$ as structure refiners.
\end{abstract}

\section{Introduction}

The Direct Sheet Plant (DSP) thin slab caster has been producing a broad range of steel grades, from Low Carbon Aluminium killed (LCAK) up to High Strength Low Alloyed (HSLA) steels. Some grades show a high risk of breakouts.

Low carbon steel is not expected to be sensitive to hot tearing and/or cracking, but an LCAK grade (see Table 1 for the chemical composition) has a high risk of breakouts due to cracking in the DSP caster. A HSLA grade, a micro-alloyed steel with extra additions of vanadium, nitrogen and niobium, has extremely low breakout occurrence. However, a similar steel grade, a low-range-HSLA (LRHSLA), with equal amount of niobium, but lower amount of vanadium and nitrogen, is also very sensitive to breakouts.

From a statistical analysis of the breakout occurrence, in 2007-2008, the possibility of a breakout for the LR-HSLA is one and a half times higher than that for a LCAK; and for a typical HSLA is four times smaller than that for a LCAK.

The casting parameters have been maintained the same in the casting trials; all steels were cast at about the same casting speeds, all with the same mould powder, the same mould and similar widths. 
The cracking sensitivity in the unbending region with a second ductility trough at around $800^{\circ}-1000^{\circ} \mathrm{C}$ is not considered here.

Table 1. Chemical composition of three DSP steel grades.

\begin{tabular}{ccccccc}
\hline $\begin{array}{c}\text { Steel } \\
\text { grade }\end{array}$ & $\begin{array}{c}\mathrm{C} \\
(\mathrm{wt} \%)\end{array}$ & $\begin{array}{c}\mathrm{Mn} \\
(\mathrm{wt} \%)\end{array}$ & $\begin{array}{c}\mathrm{V} \\
(\mathrm{wt} \%)\end{array}$ & $\begin{array}{c}\mathrm{Nb} \\
(\mathrm{wt} \%)\end{array}$ & \multicolumn{2}{c}{$\mathrm{N}(\mathrm{ppm})$} \\
\hline LCAK & 0.045 & 0.22 & - & - & - & $\mathrm{aim}$ \\
LR-HSLA & 0.045 & 0.8 & 0.04 & 0.013 & 80 & 100 \\
HSLA & 0.045 & 0.8 & 0.13 & 0.013 & 130 & 150 \\
\hline
\end{tabular}

Therefore the question is: why are the LCAK and the LR-HSLA sensitive to cracking and the HSLA is not. In this paper we will focus on the differences between LCAK and HSLA.

\section{Short literature review}

In the literature many terms regarding the phenomenon of crack formation at temperatures close to the solidus temperature such as hot tearing, hot cracking or solidification cracking can be found [1-8]. Regardless of the name, hot tears are separations, which might form during casting, when the temperatures of sub-areas of the material are between solidus $\left(\mathrm{T}_{\mathrm{S}}\right)$ and liquidus $\left(\mathrm{T}_{\mathrm{L}}\right)$, and are subject of simultaneously acting tensile stresses [6]. The deformation of the dendritic network strongly depends on its coherency state and the flow of liquid occurring in a porous solid phase [7].

As the steel first solidifies, it does so in the form of dendrites. These dendrites have no mechanical bond with each other being separated by liquid steel. Consequently, such a slurry has little or no strength. As solidification continues the individual dendrites start to connect with each other giving the solidified shell some strength (figure 1). The zero strength temperature (ZST) is defined as the temperature at which forces can first be transmitted perpendicular to the solidification direction [8]. This ZST corresponds to a fraction of solid $\left(\mathrm{f}_{\mathrm{S}}\right)$ of around 0.65 to 0.80 . At this stage of solidification a segregate rich film still exists between the dendrites; therefore a small strain leads to cracking. This results in a crack or segregate rich zone depending on whether the liquid steel can flow between the dendrites.

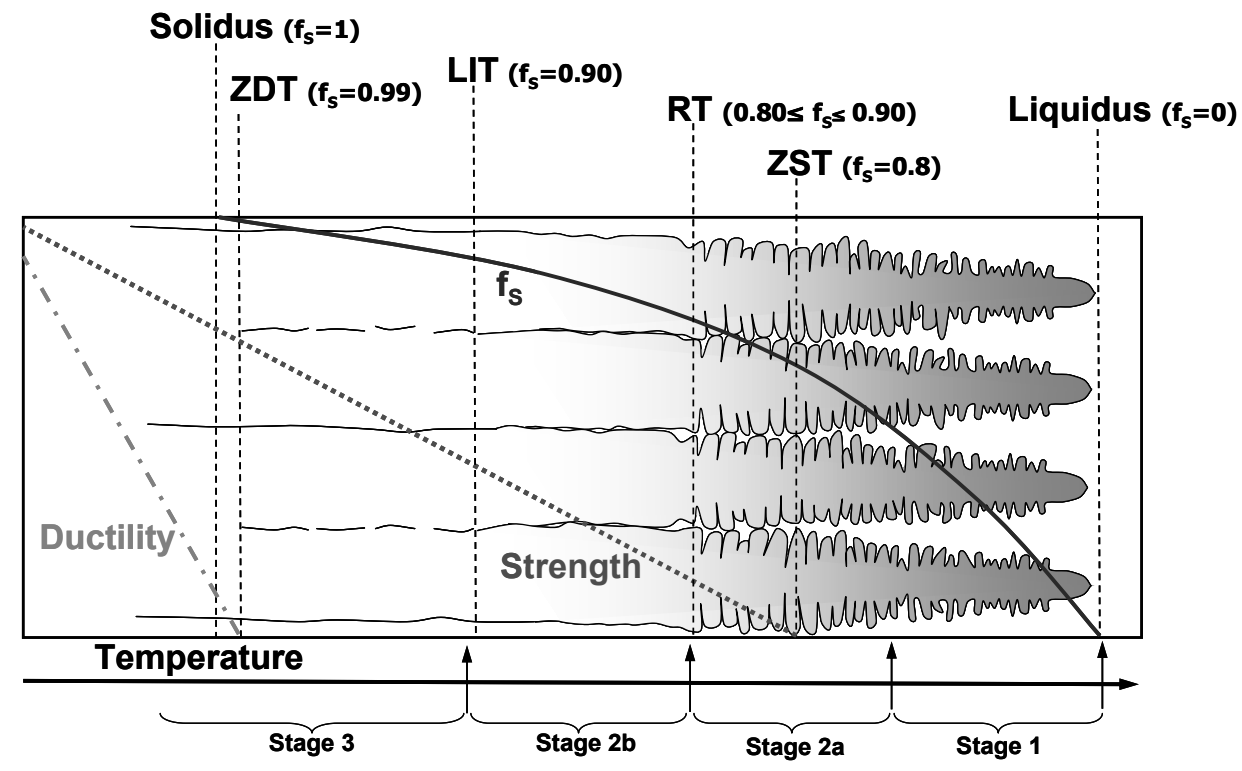

Figure 1.

Solidification structure with characteristic temperatures in hot tearing.

As the steel solidifies and cools further, the strength and ductility of the material increases $[8,9]$. The temperature at which the transition occurs from brittle to ductile behaviour is known as the Zero Ductility Temperature (ZDT) and is commonly associated with a fraction of solid $\left(\mathrm{f}_{\mathrm{S}}\right)$ between 0.98 
and 1. In Figure 1 a schematic representation of the ZST, ZDT and the solidification structure is shown.

The range between the ZST and ZDT is defined as the brittle temperature range $\left(\Delta \mathrm{T}_{\mathrm{B}}\right)$ and can be used as an indicator of hot tearing susceptibility of a particular alloy, that shows a temperature range where this alloy is susceptible to hot tearing - providing that external factors such as strain rate, stress and strain level are sufficient for hot tearing to happen.

$$
\Delta \mathrm{T}_{\mathrm{B}}=\mathrm{ZST}-\mathrm{ZDT}
$$

The wider the brittle range, the longer the period of time that the alloy spends in this range and the larger the stress concentration resulting from the shrinkage hindrance [3].

The intention of adding of small amounts of carbide and nitride formers such as $\mathrm{Nb}, \mathrm{V}$ and $\mathrm{Ti}$ is to control the austenite grain size (the particles hinder the boundary migration and grain growth) in the solid state. This, in turn, produces fine ferrite grain sizes, and by precipitation in the ferrite at lower temperatures (assisted by water cooling of the material out of the last rolling stand) gives a bonus of extra particle strengthening. These materials, the micro-alloyed or HSLA steels, mentioned above, are available in a variety of compositions [10]. Even at lower temperatures, in HSLA steels, precipitation of carbides or nitrides at the austenite or ferrite boundaries can lead to cracking in the second ductility trough [10]. By adding an appropriate concentration of these elements, the toughness, plasticity, wearand corrosion-resistant properties could be remarkably improved [11].

Until now, just a handful of studies have focused on the combined effects of $\mathrm{V}$ and $\mathrm{Ti}$ on the refining of solidification microstructures - all of them focused on casting steels.

Fu et al. [11] attributed the structure refinement from $\mathrm{V}+\mathrm{Ti}$ and rare earths (RE) additions to the segregation of these elements to the solid/liquid interface during solidification, and corresponding growth restriction effect on the iron dendrites. This is also attributing to the nucleation of iron on carbides and nitrides of $\mathrm{V}$ and $\mathrm{Ti}$ that have a lattice mismatch less than $6 \%$ with iron.

$\mathrm{Yu}$. Z. Babaskin [12] shows some experimental evidence that additions of $\mathrm{V}$ being bound with nitrogen and forming nitrides, e.g. VN, may act as structure refiners in a 40RL cast steel (see Table 2 for the chemical composition).

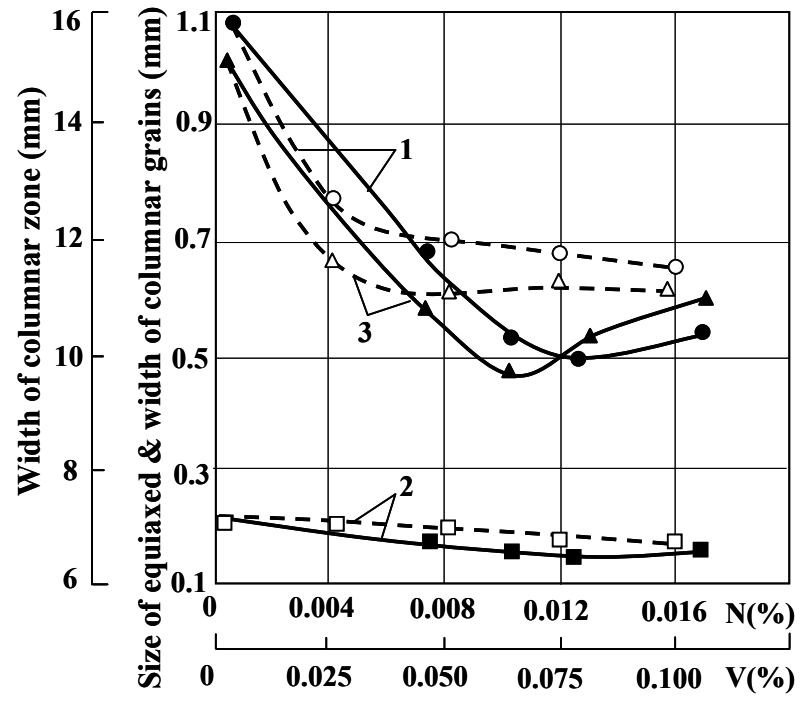

Figure 2. Effect of VN additions in a 40RL steel. (1) Width of the columnar zone, (2) average thickness of columnar dendrites, and (3) average size of equiaxed dendrites (45-mm billet; melt temperature $1560{ }^{\circ} \mathrm{C}$ ) [12]. Effect of $\mathrm{N}$ (solid lines) and $\mathrm{V}$ (dashed lines).

Figure 2 shows that the increase in combined VN addition reduces the width of the columnar zone, decreases the thickness of the columnar dendrites, and the equiaxed dendrites show the minimum size at around $0.09 \% \mathrm{VN}$. 
On the other hand, it is shown that the effect of nitrogen is more pronounced than that of vanadium. Nitrogen seems to produce a minimum in curves 1 and 3 at around $0.010 \%$ to $0.012 \% \mathrm{~N}$, while vanadium does not show this trend. Nevertheless, both elements cause the reduction in the width of the columnar zone, in the columnar dendrites average width, and in the average size of the equiaxed dendrites, when increasing $\mathrm{V}$ or $\mathrm{N}$ contents.

Table 2. Chemical composition of the 40RL steel [12].

\begin{tabular}{ccccccccc}
\hline Element & $\mathrm{B}$ & $\mathrm{C}$ & $\mathrm{Cr}$ & $\mathrm{Mn}$ & $\mathrm{Ni}$ & $\mathrm{P}$ & $\mathrm{S}$ & $\mathrm{Si}$ \\
\hline (wt \%) & $0.0025-0.005$ & $0.35-0.45$ & 0.3 & $0.5-0.8$ & 0.3 & 0.04 & 0.045 & $0.17-0.37$ \\
\hline
\end{tabular}

The grain refinement by $\mathrm{VN}$ additions was also shown in other alloyed casting steels [12]. There is also evidence in Ref. [12] that additions of VN narrow the brittle (vulnerable) solidification range and increase the hot ductility.

\section{Results}

\subsection{Microstructural evidence}

LCAK and HSLA macrostructure in figure 3 was obtained with the Bechet-Beauchard etchant. The dendrites are well seen.

The hypothesis is, that $\mathrm{V}$ and $\mathrm{N}$ react during solidification with the corresponding structure refinement of the steel [12]. This refinement should have consequences for the mechanical behaviour of the steel, favourably affecting the strength of the semi-solid steel and its ductility. Eventually the hot tearing susceptibility will be decreased.

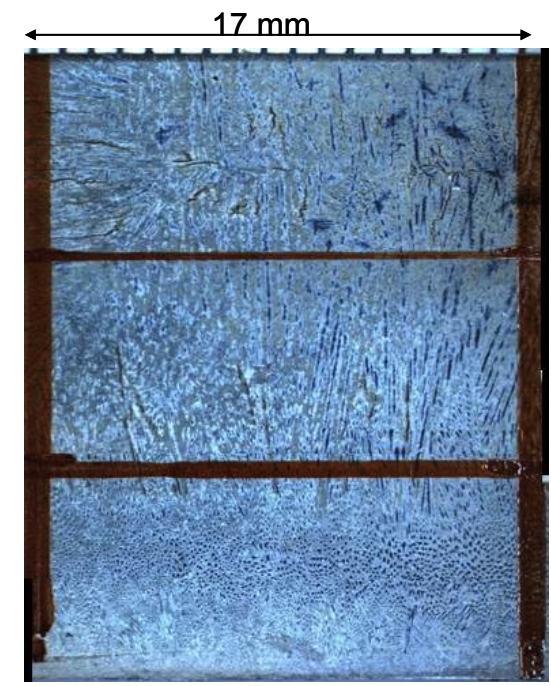

HSLA

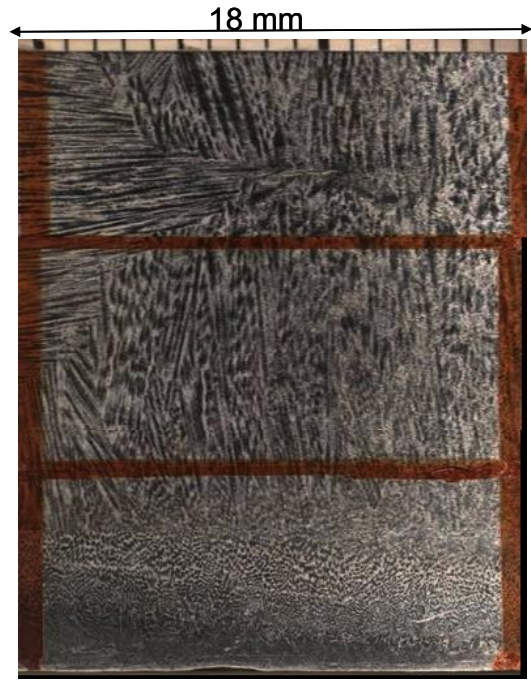

LCAK

Figure 3. Macroetching for the two steel grades considered in this study.

The macrostructures shown in figure 3 support the overall structure refinement in the HSLA steel as compared to the LCAK steel: dendrites are thinner and shorter, their internal constitution is finer. The secondary dendrite arms in the continuous cast structures of steel are difficult to see. However, the primary arm spacing is possible to measure. Figure 4 demonstrates this, although the difference is not large, the dendrites in LCAK are thicker than in HSLA. 


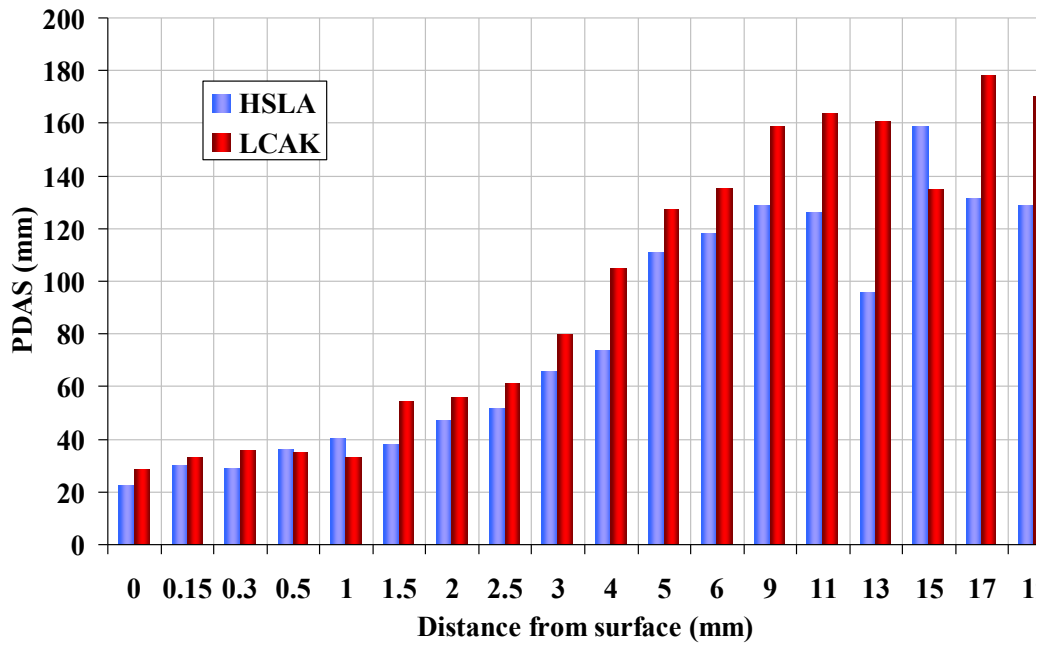

Figure 4. Primary dendrite arm spacing measured in the HSLA and LCAK steels.

\subsection{Brittle temperature range}

The range between the ZST and ZDT gives a qualitative guide to hot crack sensitivity. As can be seen in Figure 5, the ZST of LCAK (blue squares) occurs within the temperature range of $1460-1480{ }^{\circ} \mathrm{C}$. For HSLA (red circles) the ZST is somewhat lower, within a temperature range of $1420-1440{ }^{\circ} \mathrm{C}$. In general, the strength of HSLA at a given temperature within the range $1500-1300^{\circ} \mathrm{C}$ is less than LCAK.

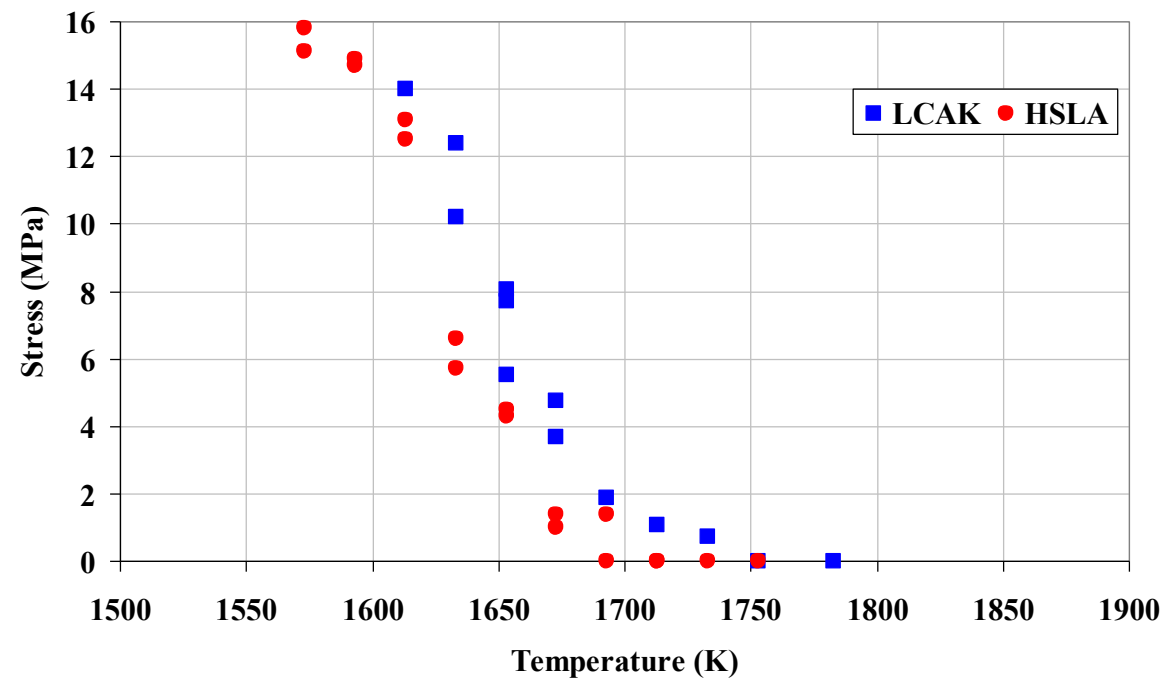

Figure 5. Tensile strength at high temperatures $\left(1300-1500{ }^{\circ} \mathrm{C}\right)$ of grades LCAK and HSLA [13].

Figure 6 shows the tensile specimens after testing. For LCAK, the ZDT occurs in the temperature region of $1400-1420^{\circ} \mathrm{C}$. This is evident from the flat fracture surface (no ductile cone) and no elongation. As the temperature decreases, the elongation/ductility increases. This is clearly noticeable in the sample tested at $1340^{\circ} \mathrm{C}$.

For HSLA, the ZDT is in the temperature range of $1380-1400^{\circ} \mathrm{C}$. Again, as the temperature decreases the ductility increases.

\section{Conclusions}

The study of the LCAK and HSLA steel grades shows that the addition of microalloying elements can have an unexpected effect on the microstructure that, as a consequence, influences the thermomechanical properties of this grade during solidification. 


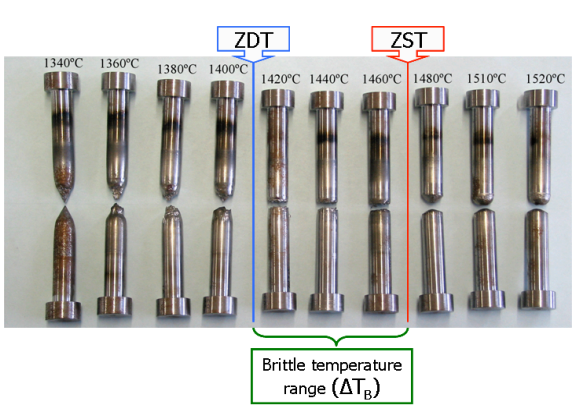

LCAK

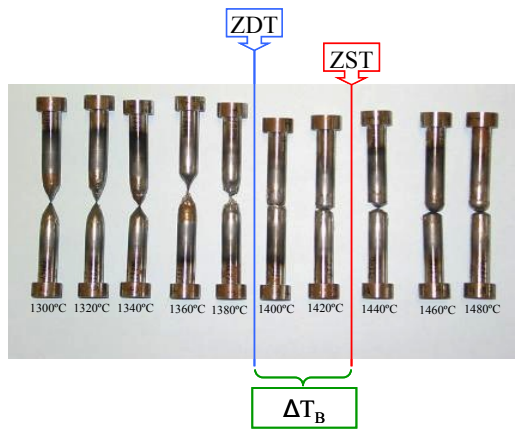

HSLA
Figure 6. Post mortem hot tensile samples and measurements, showing also the ZST, ZDT and brittle temperature range [13].

The as-cast microstructure of a HSLA is finer compared with the LCAK grade under the same casting conditions, apparently as a result of the microalloying additions. The observed result agrees with the trend reported earlier for alloyed casting steels.

It is also shown that the brittle temperature range and the strength are shorter and lower, respectively, in the semi-solid HSLA grade than in the LCAK, showing a positive effect in reducing the hot tearing susceptibility of the HSLA steel grade.

Nevertheless, the brittle temperature range is only an indicator of the susceptibility of a particular alloy at a particular temperature range, where this alloy is vulnerable to hot tearing, providing, that external factors such as strain rate, stress and strain level are sufficient for hot tearing to happen.

\section{Acknowledgements}

This research was carried out under project number M41.5.08320 within the framework of the Research Program of the Materials innovation institute M2i (www.m2i.nl). The hot tensile tests done in Sumitomo Metal Industries, Japan, are gratefully acknowledged.

\section{References}

[1] Dantzig J A and Rappaz M 2009 Solidification (Laussane: CRC Press)

[2] Eskin D, Suyitno and Katgerman L 2004 Progress in Materials Science 49 629-711

[3] Eskin D and Katgerman L. 2007 Metallurgical and Materials Transactions A 38A 1511-1519

[4] Feurer U 1977 Quality Control of Engineering Alloys and the Role of Metals Science (Delft: Delft University of Technology) 131-145.

[5] Nakagawa T, Umeda T, Murata J, Kamimura Y, and Niwa N 1995 ISIJ International 35723 729

[6] Pierer R, Bernhard C, and Chimani C 2007 La Revue de Metallurgie (2) 72-83

[7] Rappaz M, Drezet J M, and Gremaud M 1999 Metallurgical and Materials Transactions A 30A $449-455$

[8] Won Y M, Yeo T J, Seol D J, and Oh K H 2000 Metallurgical and Materials Transactions 31B 779-794

[9] Chojecki A, Telejko I, and Bogacz T 1997 Theoretical and Applied Fracture Mechanics 27 99105

[10] Emi T and Cramb A W 2003 The Making Shaping and Treating of Steel (Pittsburg, USA: The AISE Steel Foundation)

[11] Fu H, Qu Y, and Xing J 2009 Journal of Materials Engineering and Performance 18 333-338

[12] Babaskin Y Z 1980 Structure and properties of cast steel (Kiev: Naukova Dumka (in Russian))

[13] Santillana B, Boom R, Eskin D, Campaniello J, Mizukami H, Hanao, M, and Kawamoto M 2010 The 2nd International Symposium on Cutting Edge of Computer Simulation of Solidification and Casting-CSSC 2010. Poster Presentation (Sapporo, Japan) 